\title{
Seismic Performance of Fire Exposed Moment Resisting Composite Frame
}

\author{
Ms. Suhaila Fasini T.K. ${ }^{1}$ \\ ${ }^{1}$ P.G. Student, \\ (Structural Engineering Department), \\ Sree Narayana Gurukulam College of Engineering \\ Kadayiruppu, India.
}

\author{
Ajith A.V. ${ }^{2}$ \\ ${ }^{2}$ Associate Professor, \\ (Structural Engineering Department), \\ Sree Narayana Gurukulam College of Engineering \\ Kadayiruppu, India.
}

\begin{abstract}
In the area of moderate-to-high seismicity, most of the buildings have issues from Post-earthquake fires. These post-earthquake fires are lead to the damage of fire protection techniques. Such earthquakes are lead to the damage of fire resistance techniques. This damage may be caused, the building components are directly exposed to the fire exposure. In the building, the steel components are subjected to maximum fire temperature, which slowly cools to ambient temperature. After such fire exposure, some of the building components needed to be rehabilitated for their reuse. However, most of the literature discusses the seismic performance of fire exposed steel frames. But this study developed a simple computational scheme to investigate the seismic performance of fire exposed composite frames. The simulation responses demonstrate the vulnerability of the post-earthquake fire exposed composite frame buildings. The response of moment resisting composite frame to postearthquake fire is investigated and compared with the response of the without fire exposed composite frame. And also study the firefighting capability of the protected fired composite frame, using numerical analysis performed using commercial finite element software.
\end{abstract}

Keywords-Composite frame; Fire exposure; Seismic performance; Cyclic loading; Non-linear finite element analysis

\section{INTRODUCTION}

In urban areas, major earthquakes are lead to building fires. Post-earthquake fire losses can be equal to or more than the losses caused by the earthquake themselves. In seismic regions, steel components are mainly used, due to some advantages they offer including being lightweight and possessing high ductility. To maintain stability and integrity of composite steel structures during a fire, fire insulation such as sprayed fire resistive material (SFRM) is commonly applied on the surface of the composite steelwork. Fire insulations are mainly used in the building to reduce the effect of temperature on the components during a fire accident. From past events, post-earthquake fire accidents are damaging active fire protection systems such as sprinklers, which reduce the firefighting capability of the building. Hence, fire insulation has a critical role in the response of post-earthquake fire on the building. After fire exposure, some building structures can sustain without collapse, their reparability and reusability are mainly dependent on the measure of structural damages. Consequently, a widely used general rule for fire-exposed steel buildings is that if the members are reasonably straight with no visible distortion, then it is fit for reuse. During a fire, peak temperature usually varies along the length and depth of the fire-exposed members, which leads to material heterogeneity in the member upon cooling. Fire-surviving heterogeneous composite steel member performance in the future earthquake is not known. [1,3]

\section{OBJECTIVE}

- To study the seismic performance of the fired two-bay composite frame.

- To compare the seismic performance of a two-bay composite frame with and without fie exposure.

- To study the firefighting capability of the two-bay composite frame under post-earthquake fire exposure.

\section{METHODOLOGY}

This study comprehensively investigates the seismic performance of fired two-bay composite frames with and without coating by using ANSYS 16 software. And the seismic performance of without fired two-bay composite frame was also investigated.

\section{DESCRIPTION OF THE INVESTIGATED STRUCTURES}

Numerical modeling of the composite frame was performed by the finite element software ANSYS 16 WORKBENCH. The investigations performed on welded beam-to-column joints, with columns realized as concretefilled tubes (CFT) with rectangular hollow sections (RHS). Direct connection of the beams to the rectangular hollow section tubes would not satisfy the requirement of full strength and rigid joints, mainly due to the flexibility of the front wall of the tube under tension or compression. Consequently, to transfer the loads from beam flanges to the sidewalls of the column, a connection solution was adopted based on the use of stiffening plates welded around the steel tube in the shape of an external diaphragm. Cover plates are used to reinforce the beam-column connection, forcing the plastic hinge to form in the beam. The cover plates are welded to the external diaphragm using full penetration butt welds. [3]

The beams were designed from steel (ISMB 400) with a $2.47 \mathrm{~m}$ length and the columns from high strength steel (S460) and M25 concrete with a height of $4.26 \mathrm{~m}$. An external diaphragm is shop-welded to the column to transfer the forces from the beam to the sidewalls of the column. Beam flanges are 39 welded to the external diaphragm using full-penetration butt welds. A shear tab bolted connection between the beam 
web and vertical column stiffener was considered for erection only. The final connection of the beam web is realized using full penetration weld, using the shear tab as a backing plate. The shear tab size $150 \times 700 \mathrm{~mm}$ with a thickness of $15 \mathrm{~mm}$. The CP joint connects a wide-flange hot rolled beam with a CFT column using field welding. The dimension of the cover plate is $200 \times 500 \times 15 \mathrm{~mm}$. and the dimension of the external diaphragm is $600 \times 600 \times 20 \mathrm{~mm}$. The material properties given for the model are shown in Table 4.1. [3]

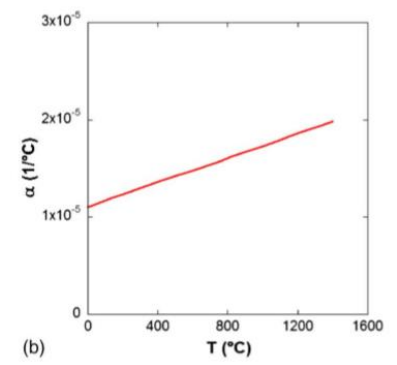

(a) Coefficient of thermal expansion

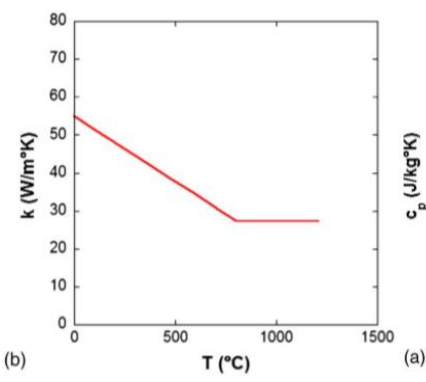

(c) Thermal conductivity

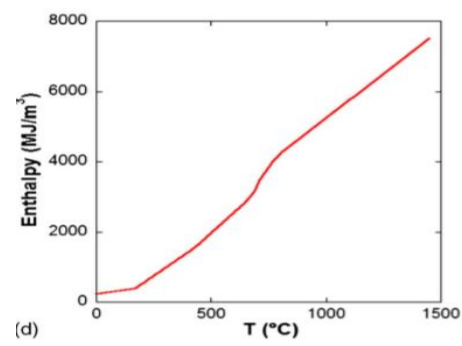

(e) Enthalpy

Figure 4.1: Thermal Properties of Composite Frame

Table 4.1: Material Properties of Composite Steel Frame

\begin{tabular}{|c|c|c|}
\hline PROPERTY & CONCRETE & STEEL \\
\hline Material & M25 & S460 \\
\hline $\begin{array}{c}\text { Modulus of } \\
\text { Elasticity }\end{array}$ & $32387 \mathrm{~N} / \mathrm{mm}^{2}$ & $2 \times 10^{5} \mathrm{~N} / \mathrm{mm}^{2}$ \\
\hline Poisson's Ratio & 0.2 & 0.3 \\
\hline Density & $25000 \mathrm{~kg} / \mathrm{m}^{3}$ & $7850 \mathrm{~kg} / \mathrm{m}^{3}$ \\
\hline
\end{tabular}

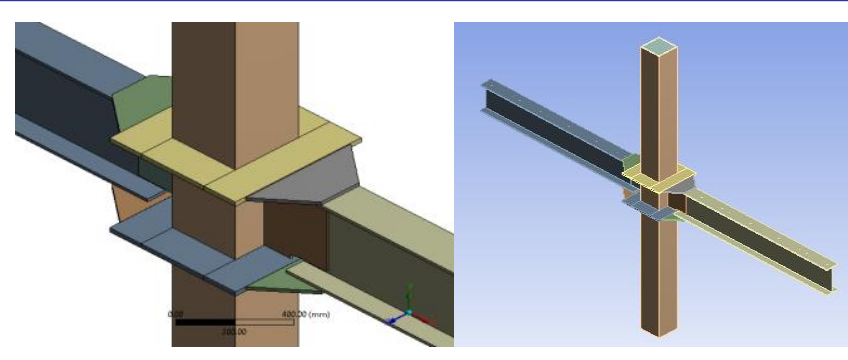

Figure 4.2: Modelled Isometric View of Interior Join of a Composite Frame Model

For the investigation of seismic performance of fired composite frame five models were used, that is bottom right fired model (BRF), bottom left fired model (BLF), top right fired model (TRF), top left fired model (TLF) and without fired model (WOF). The column was assumed to be fixed at both ends. To create the plastic deformation in the connection components, a combined hardening rule (Isotropic-Bilinear) with the Von Mises criterion was applied. Displacement is applied at the tip of the beam according to the SAC loading protocol shown in Figure 4.3.

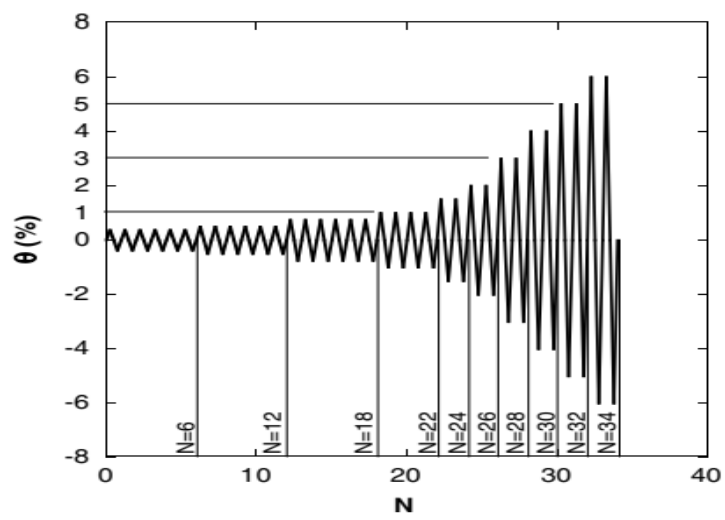

Figure 4. 3: SAC Loading Protocol

For the thermal analysis, thermal loading was given to the interior joint of a composite frame in eight different fire exposure cases. For the thermal analysis, a fire temperature curve representative of a post-earthquake fire scenario needed to be used. Figure 4.4 shows Fire pattern according to ISO834 and ASTM E119. And initial temperature provided as $22^{\circ} \mathrm{C}$. Figure $4.5,4.6,4.7$ and 4.8 shows fire exposed different composite frame models.

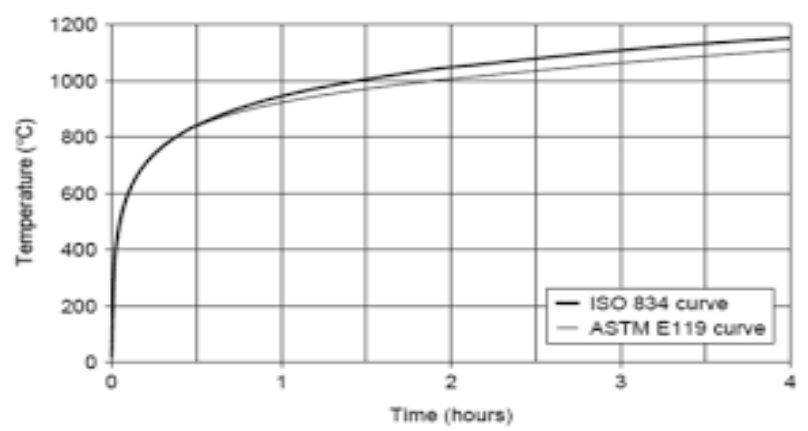

Figure 4.4: Fire Pattern According to ISO834 and ASTM E119 


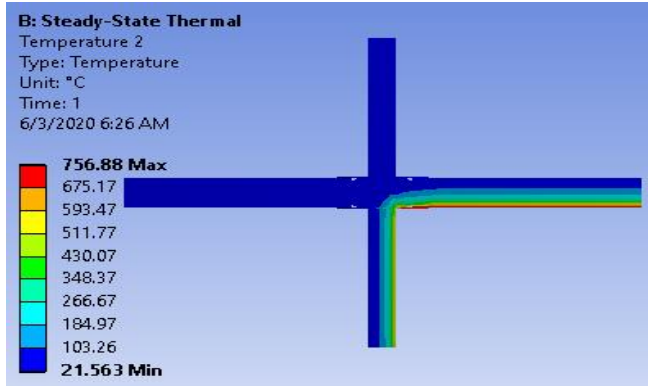

Figure 4.5: Bottom right fired (BRF) model

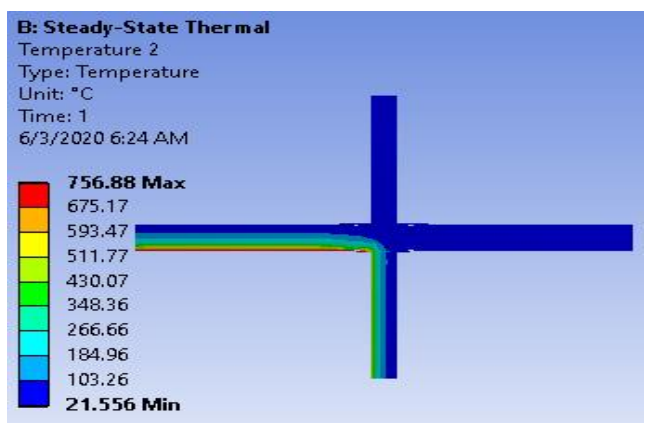

Figurre 4.7: Bottom left fired (BLF) model

\section{RESULT AND DISCUSSIONS}

\section{i. Equivalent Plastic Strain of Models}

The equivalent plastic strain distribution in five models with and without protection coatings are displayed in figure 5.1, 5.2, 5.3, 5.4, and 5.5. Figure 5.1 shows the equivalent plastic strain distribution in WOF (without fire) model. From the figure, it can be found that plastic strain is concentrated in the face of the beam and which indicates that the connection is not strong. Hence, plastic hinges are created in the beam sections instead of a column. In the case of bottom fired models, plastic hinges are created at columns. Fired composite frame models created more plastic hinges than the WOF model. Coated composite frame model figure shows that plastic strains are concentrating in the beams, which is less than the unprotected models.

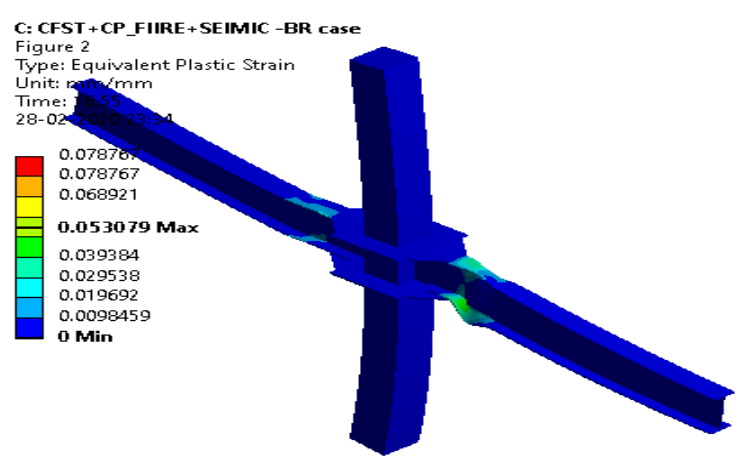

Figure 5.2: Equivalent Strain Distribution in BRF (Bottom right fired model)

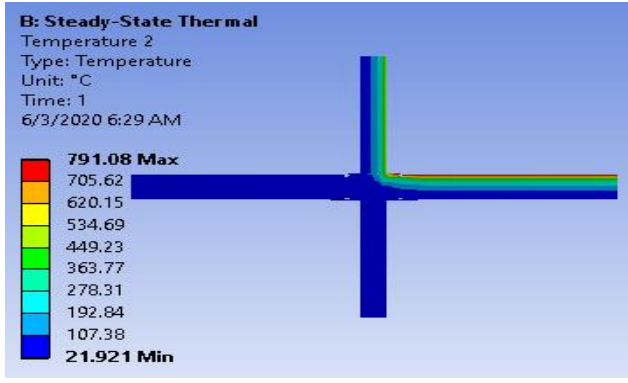

Figure 4.6: Top Right Fired (TRF) Model

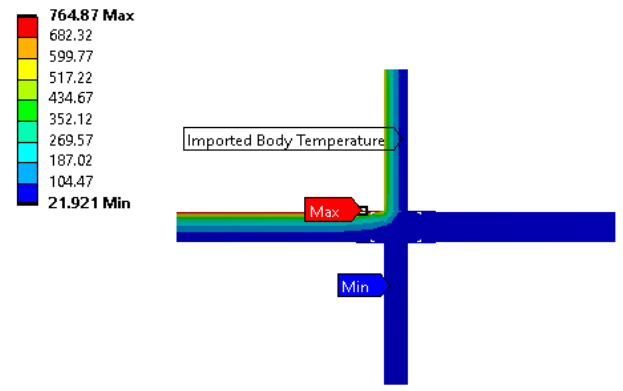

Figure 4.8: Top Left Fired (TLF) Model

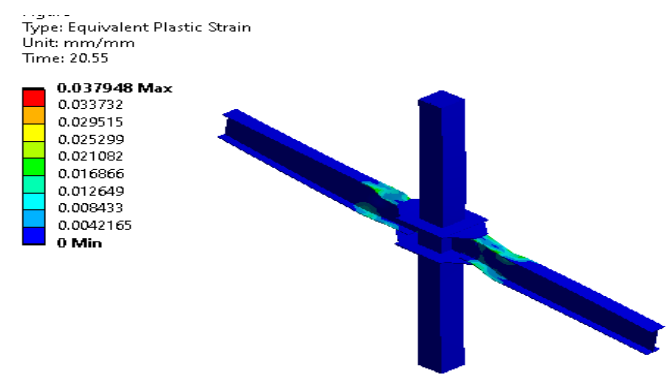

Figure 5.1 Equivalent Strain Distribution in WOF (Without fired model

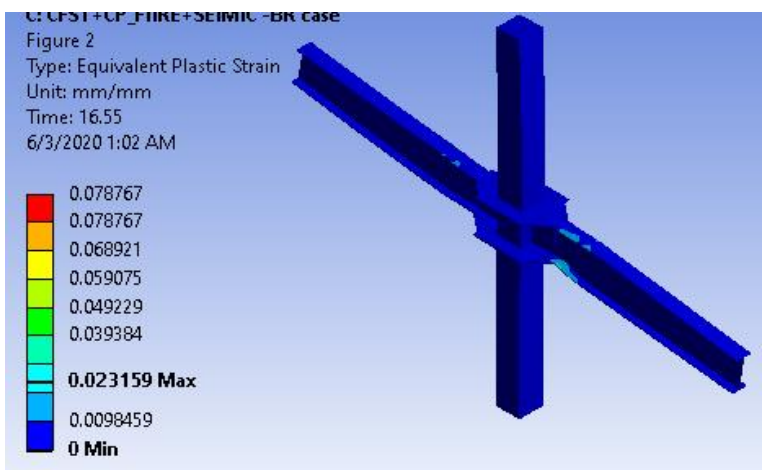

Figure 5.3: Equivalent Strain Distribution in CBRF (Coated bottom right fired model) 


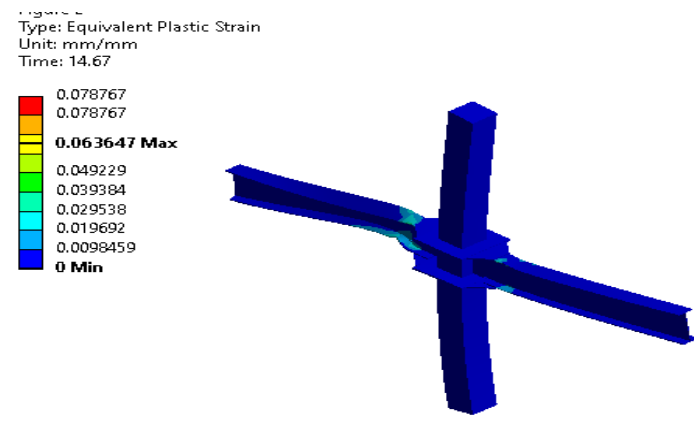

Figure 5.4: Equivalent Strain Distribution in BLF (Bottom left fired model)

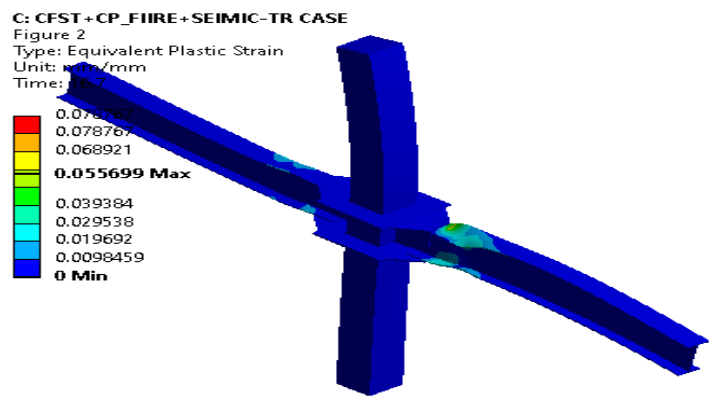

Figure 5.6: Equivalent Strain Distribution in TRF (Top right fired model)

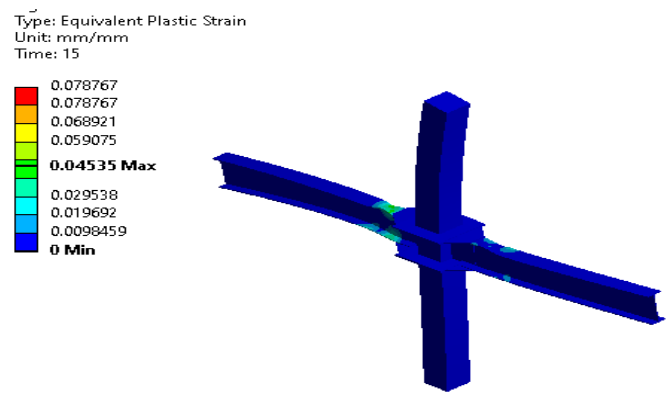

Figure 5.8: Equivalent Strain Distribution in TLF (Top left fired model)

ii. Hysteresis Response of models

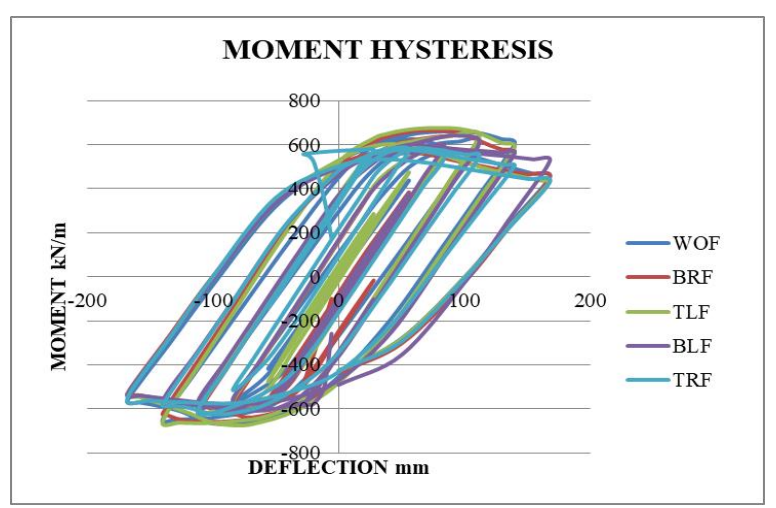

Figure 5.10: Moment-Deflection Hysteresis Response of Unprotected Composite Frame Models (Right beam)

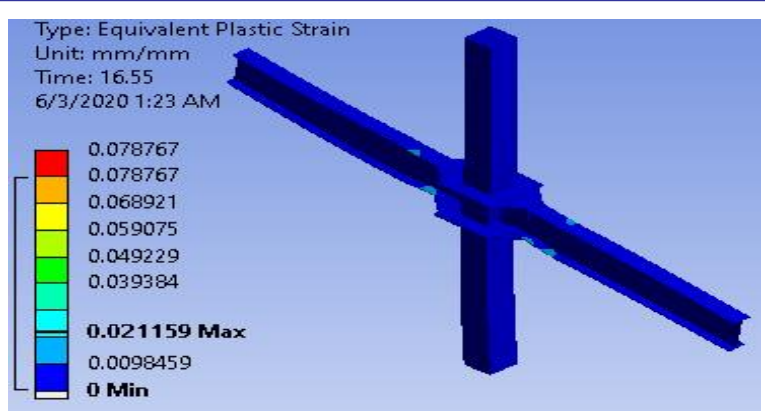

Figure 5.5: Equivalent Strain Distribution in CBLF (Coated bottom left fired model)

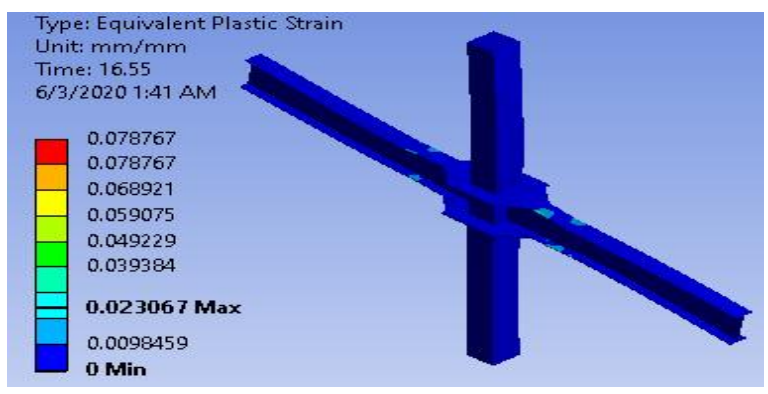

Figure 5.7: Equivalent Strain Distribution in CTRF (Coated top right fired model)

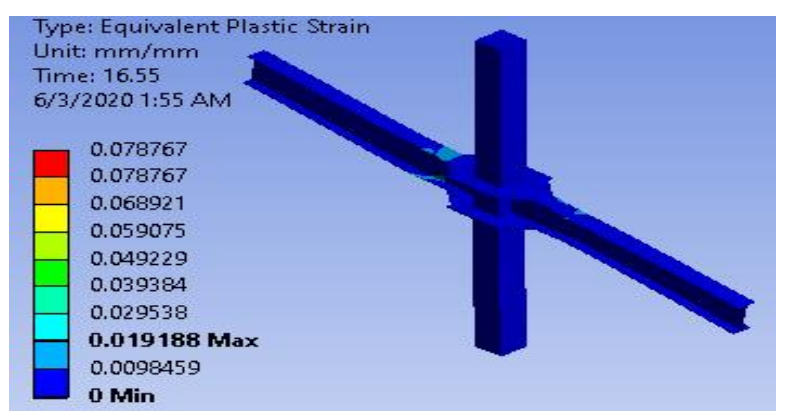

Figure 5.9: Equivalent Strain Distribution in CTLF (Coated top left fired model)

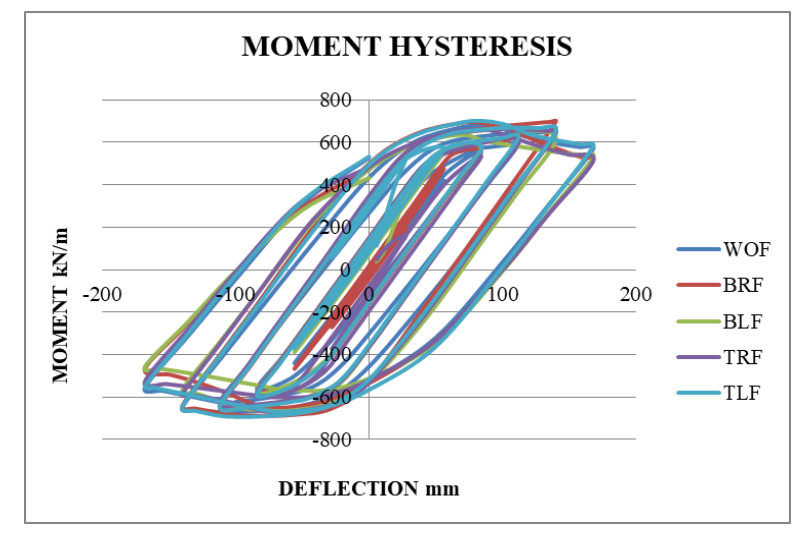

Figure 5.11: Moment-Deflection Hysteresis Response of Unprotected Composite Frame Models (Left beam) 


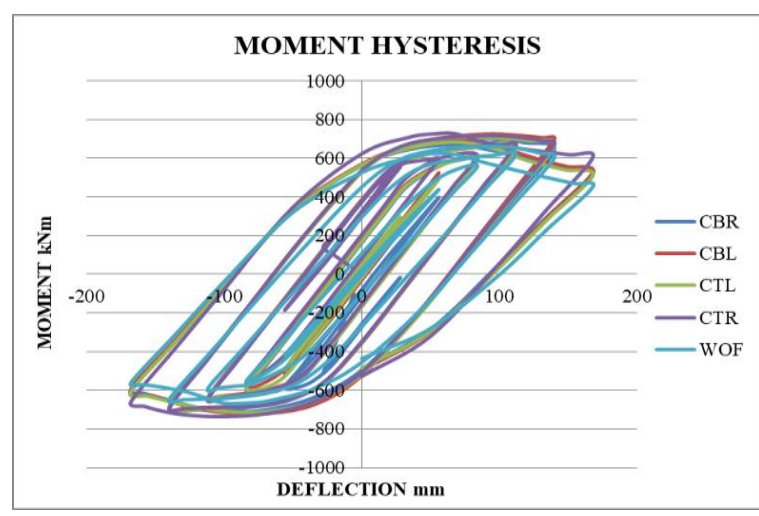

Figure 5.12: Moment-Deflection Hysteresis Response of Protected Composite Frame Models (Right beam)

The hysteresis response of five unprotected models and protected models are shown in figure 5.10, 5.11, 5.12, and figure 5.13. From the figure, the connection without fire exposure shows the development of a plastic hinge with symmetric moment- rotation hysteresis response. But in fired models shows an unsymmetric moment-hysteresis response, because of under fire exposure material properties of the connection changes to the heterogeneous.

\section{iii. Stiffness}

The stiffness of the models was calculated from hysteresis curves using the stiffness formula,

$$
\text { Stiffness }=(\mathrm{F} \max -\mathrm{F} \min ) /(\mathrm{d} \max -\mathrm{dmin})
$$

From figure 5.14, stiffness of the protected and unprotected fired composite frame models was compared. From the figure, it can be found that the higher stiffness value occurs on top floors while comparing with the bottom floors. Hence the top floor is stiffer than bottom floors. This indicates that the fire exposure transforms the building to a weak column-strong beam mechanism. Consequently, under seismic loading, a fire exposed building may develop the single-story mechanism commonly known as the soft story mechanism, which may lead to the unexpected failure of the structure.

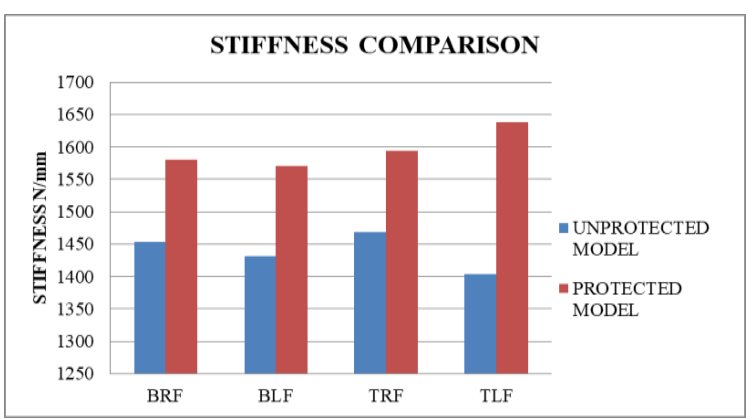

Figure 5.14 Stiffness Comparisons of Various Protected and Unprotected Models

\section{CONCLUSION}

The seismic behavior of the composite frame under fire exposure was studied under thermal loading and cyclic loading using numerical analysis. The following conclusions are derived from the present study:

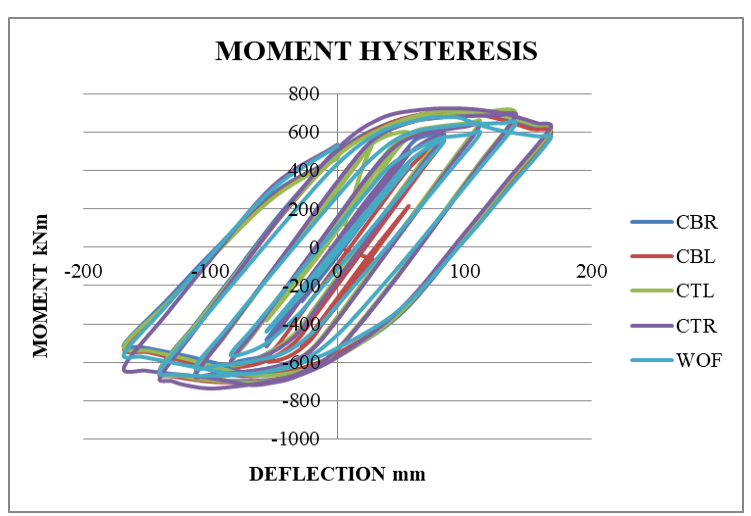

Figure 5.13: Moment-Deflection Hysteresis Response of Protected Composite Frame Models (Left beam)

1. Top floors exposed to fire, the beam top flange exhibited more deformation compare to the bottom flange. This is exhibited because of the top flange was directly exposed to $1000^{\circ} \mathrm{C}$, whereas the bottom flange remains at the ambient temperature.

2. In fire exposed connections, plastic strains mainly concentrated in beams thereby creating plastic deformation in the face of the beam.

3. The fire exposed composite frame shows an unsymmetrical moment hysteresis response, due to the material properties of the connection under fire exposure changes to heterogeneous. But in without fire composite frame shows a symmetrical moment hysteresis response, due to their homogeneous material property.

4. The firefighting capability of protected different composite frame models is very high than the unprotected models. Hence, in protected models coating is acts as fire insulation.

5. The overall strength of the connection under fire exposure reduced when compared to the connection without fire exposure. And strength during positive bending degraded gradually, whereas the strength during negative bending degraded at a faster rate.

6. An inflection point developed between the relatively stiff top floor and the weak bottom floor. This indicates that the fire exposure transforms the building to a weak column-strong beam mechanism. Consequently, under seismic loading, a fire exposed building may develop the single-story mechanism commonly known as the soft story mechanism, which may lead to the unexpected failure of the structure.

\section{REFERENCES}

[1] S. Quayyum, A.M.ASCE, and H. Tasnim, "Initial residual stresses in hot-rolled wide-flange shapes: a computational technique and influence on structural performance," Journal of structural engineering, ASCE, 2017, pp. 1-15.

[2] S. Quayyum, A.M.ASCE, and H. Tasnim, "Seismic performance of a fire-exposed moment-resisting frame,"Journal of structural engineering, ASCE, 2018, pp. 1-17.

[3] C. Vulcu, et.al., "Beam-to-CFT high-strength joints with external diaphragm. II: numerical simulation of joint behavior," Journal of structural engineering, ASCE,2017. 